Article

\title{
Energy Transition Scenarios and Their Economic Impacts in the Extended Neoclassical Model of Economic Growth
}

\author{
Lukáš Režný(i) and Vladimír Bureš *®i) \\ Faculty of Informatics and Management, University of Hradec Králové, Rokitanského 62, 50003 Hradec Králové, \\ Czech Republic \\ * Correspondence: vladimir.bures@uhk.cz; Tel.: +420-49-333-2259
}

Received: 17 June 2019; Accepted: 29 June 2019; Published: 2 July 2019

\begin{abstract}
Introduction: Energy return on energy invested (EROEI) of fossil fuels has been declining sharply, while modern renewable energy sources generally have even lower EROEI than fossil fuels. It has been repeatedly proven that economic growth expressed in the form of growth of real Gross Domestic Product (GDP) is closely related to intensified energy consumption and escalated usage of natural resources in general. This problem remains scarcely explored in pure economic modelling. Objectives: This study presents a novel model titled Energy Extended Neoclassical Growth Model (EENGM), which focuses on the consequences of declining quantity and quality of extractable fossil fuels and lower quality of the succeeding renewable energy technology for economic growth. Method: The Neoclassical growth model is translated into a system dynamics format and is extended by important feedback mechanisms, which are identified as important from the literature and mostly missing from the analyzed system dynamics models with a similar scope. Two scenarios assess the EENGM performance: business as usual (BAU) and the sustainability strategy (SUS). Results: Sensitivity analysis is performed for the Energy Return on Energy Invested (EROEI) parameter and results in the investment share in GDP varying between 27 and $40 \%$, while the energy sector investment largely displaces investment in other economic sectors. The EENGM is associated with new behavior whereby the underperforming energy sector limits GDP growth and seizes most of the available investment. The adoption of the SUS strategy causes $28 \%$ lower cumulative fossil fuel aggregate consumption which still corresponds to higher than $1.5^{\circ} \mathrm{C}$ global warming compared to the preindustrial levels. Conclusion: The share of consumption in the GDP of an economy undergoing energy transition can approach levels previously seen only in totally war-oriented economies. Even omitting other negative environmental feedback, the feasibility of the successful energy transition of the system in its contemporary form, with the currently available renewable energy technology, seems to be highly uncertain.
\end{abstract}

Keywords: economic dynamics; energy transition; neoclassical growth model; EROEI; feedback structure; system dynamics

\section{Introduction}

Energy return on energy invested (EROEI) represents one of the major characteristics of energy sources. The higher it is, the more energy is free to fuel human economic activities. On the other hand, its decline indicates that a proportionately higher share of obtained energy from a given source has to be used in the energy extraction process instead of powering other economic activities. This usually means a higher price of a given energy source and more extensive use of capital during the production process itself. The Meta-analysis performed by Hall and colleagues points out to rapidly declining 
EROEI of major fossil fuels, with renewables having only a fraction of EROEI previously bestowed by high-quality fossil fuels century ago [1,2]. The ongoing transition to renewable energy sources thus might have serious long-term economic consequences.

EROEI is a means of quantitative evaluation of the quality of various fuels by reckoning the ratio between the energy provided by a particular fuel to society $\left(E_{\text {output }}\right)$ and the energy needed for its capturing and distribution of this energy $\left(E_{\text {input }}\right)$ [2].

$$
\text { EROEI }=\frac{E_{\text {output }}}{E_{\text {input }}}
$$

EROEI of fossil fuels declined sharply from the values of around 100:1 to a more recent 18:1 [1,2]. From the renewable energy sources, only the Hydropower has EROEI comparable to early fossil fuels, but its extensibility is limited, probably to not more than $80 \%$ above its current capacity [3]. Modern renewables (Solar PV and Wind power) generally have lower EROEI than Fossil fuels, except imported oil and gas, which seems to be comparable with Wind power $[1,2]$.

This problem of low EROEI values was very well summed by Pickard [4]: "In summation, as the Age of Fossil Fuels draws to a close, it appears that mankind may be facing an obligatory change to renewable fuel sources without having done due diligence to learn, whether, as envisioned, those renewable sources can possibly suffice."

This problem remains mostly unaddressed in purely economic modelling (notable and rare exceptions are Refs. [5,6]), which treats the surrounding environment as an unfortunate externality. Analysis of historical data repeatedly reveals that economic growth, expressed in the form of growth of the real gross domestic product (GDP), goes hand in hand with rising energy consumption and all natural resources in general [7-10]. Professor Steve Keen [11] pointed out recently: "The abiding weakness of all schools of economics, ever since the Classicals-including today's Neoclassical and Post Keynesian schools, which are normally at pains to point out how superior one is to the other-is this failure to acknowledge the key role of energy in production". This blindness is in stark contrast to the modelling approach of System Dynamics, which thoroughly takes into consideration various relationships between an economy and its environment and the accumulation of non-renewable and renewable resources, single products, and its sinks (such as released greenhouse gases or waste disposal costs) during model development. The influential work Limits of Growth relates to existing pollution problems to finite availability of non-renewable natural resources. It points out that this type of issue will negatively influence the value of economic indicators such as economic growth [12]. Although the study was accepted only by ecological economists, Graham Turner compared the study scenario with real-world data and figured out that the study was extraordinarily accurate [13]. Moreover, Bardi stressed that not all critics of the study really comprehended the original study and thus their criticism is not as relevant as it could be [14].

Since 1972, many models have used the system dynamics approach, illustrating the problems of resource depletion and climate change caused by continuing economic growth [15-18]. However, these models failed to change the economic theory in any appreciable way, even though they represented empirical facts in the relevant fields of science. Takuro Uehara et al. [19] summarized the problem concisely: "While system dynamicists may not rely heavily on economic theory because of the seemingly unrealistic assumptions employed, economists are indifferent to models that seem to disregard economic theory".

An example of such a system dynamics model which omits economic interpretation of the problem altogether is the SET model developed by Sgouridis et al. [3] and World Limits Model developed by by Capellán-Pérez et al. [20] (more elaborated economy sector is currently being added to the model under the MEDEAS EU project). Selected existing models with feedback structures are presented in Appendix A.

The model presented in this study called EENGM, Energy Extended Neoclassical Growth Model, aims to bridge this gap through the adoption of a standard, Solow-Swan model of economic growth 
translated into a system dynamics format. Representation of the model in system dynamics format enables its easy extension with the energy sector based on the main stocks, variables and feedbacks identified in the empirical literature focused on the energy-economy nexus. With this novel approach identified by Radzicki [21], EENGM explores the implications of declining EROEI for economic development while overcoming the limitations of the previously mentioned models.

The remainder of the paper is structured as follows. The introductory section is followed by the description of applied methods. The third section presents the existing model that represents the main modelling starting point, an outline of the model structure and its parametrization, the basic model behaviour, and finally a sensitivity analysis. After a discussion of the acquired outcomes, the paper concludes.

\section{Materials and Methods}

This study analyzes the existing representative models developed by means of the system dynamics methodology, which copes with the issues of resource depletion and climate change. The analysis focuses on the common models' assumptions and conclusions as well as on the form of production functions used-see the Appendix A. These findings are then used in the next step, which comprise the selection of a representative model of economic development, its conversion into the system dynamics format, and its extension with the energy sector, comprised of selected important feedback and stocks, to represent the ongoing energy transition. Detailed description of the method used for the EENGM development is the main subject of our previous work, presented in the article Adding Feedbacks and Non-Linearity to the Neoclassical Growth Model: A New Realm for System Dynamics Applications [22]. The energy transition currently only mildly influences economic growth, but has the potential to play a decisive role in the future. Can the current rate of economic growth be maintained with the currently available renewable energy sources technology? For how long can the current stock of fossil fuels support economic growth? The Energy-extended Neoclassical Growth Model (EENGM) presented in this paper is intended to help to answer these questions. The EENGM respects the rule of thumb stating that a model should be "as simple as possible". The model is thus relatively easily understandable, analysable and interpretable, which complies with the rule that a model should be "mind sized" [23]. In this form, it should convey to readers selected challenges that the economic growth process faces in the 21st century. Figure 1 is a simplification representing the development of EENGM.

We have presented the research gap in the introduction. Sections 2.1 and 2.2 take a look at the following element, Identification of the main Energy-Economy feedbacks. Section 2.4 is focused on their implementation into the model, which also covers the parameter settings. Calibration is the content of Appendix B, with sensitivity analysis along with analysis of the results being described in Section 4. The model was implemented in the software Stella, Version 9.1.3 (run under operating systems Windows 10, 8.1 and 7). 


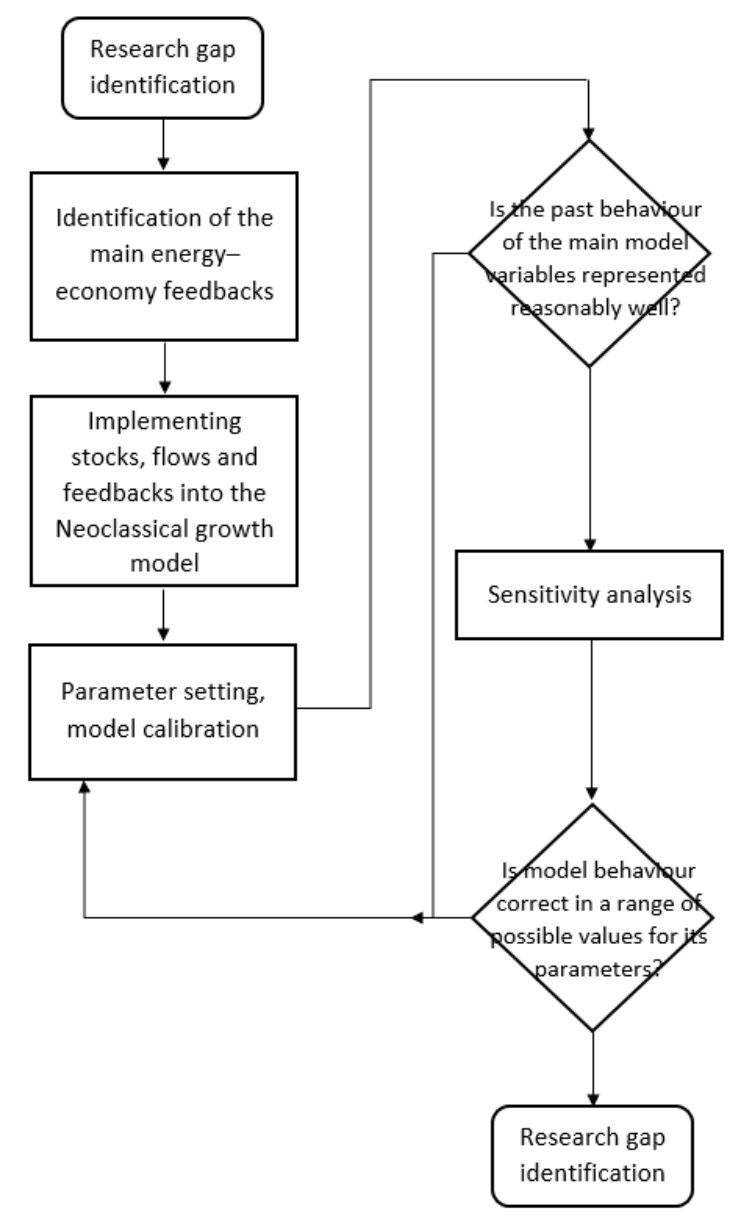

Figure 1. Flowchart depicting EENGM development.

\subsection{Relation of Economic Growth and Energy Consumption}

It has been repeatedly proven that economic growth expressed in the form of growth of the real GDP is closely related to intensified energy consumption and escalated usage of natural resources in general. An example is the economy of the US, where, from 1949 to 2009, the correlation between GDP growth and energy consumption growth was equal to 0.934 [8]. Smil obtained a similar result for the economy of Japan [9]. Brown et al. [7] analysed the data for 220 nations over a 24-year-long period (1980-2003) and found a strong correlation between the per capita energy use and the per capita GDP. An explanation for this phenomenon is the augmentation of human labour with capital. Most capital goods that are currently used are in one way or another dependent on various inputs of energy, be it from gasoline or electricity, to be usable in the production process. Human labour has mostly been reduced to the role of operating capital or serving as a sensory input in supervisory and decision-making roles [24]. From that viewpoint, fossil fuels were the enablers of the Industrial Revolution and the subsequent continuing economic growth. Stern pointed out that as the scarcity of energy grows, a strong constraint on the growth of the economy can be experienced [25]. However, the abundance of energy has a much reduced effect on economic growth. This is also the conclusion of a study of 200 years of data for the Swedish economy [25]. Hamilton [26] further pointed out that $80 \%$ of recessions experienced since 1970 in the US have a close connection to oil price shocks.

The bell-shaped extraction curve is known as the Hubbert curve and describes the extraction rate of specific non-renewable resources during a certain period. It is a result of interactions between a growing economic system and a finite resource base upon which it is dependent.

Real resource extraction curves are deformed in many ways, marked by many different real-world events, but they usually remain similar to the model case. The Hubbert curve can be used to model the 
extraction of non-renewable resources, including predictions of peak extraction, but it should be used with extreme caution. Hubbert employed it in 1956, when he estimated the total recoverable reserves of conventional crude oil for the lower 48 US states to be somewhere between 150 and 200 billion barrels. According to that range, he placed peak crude oil production in the lower 48 US states between 1965 and 1970 [27]. In 1970, the region experienced a peak in crude oil extraction, proving the first successful application of Hubbert's model. There is no breath-taking precision in this; the peak was predicted in 1956 and placed within a 5-year range, roughly 10 or so years before it happened. Still, we should not forget that, at that time, it was a rather heretical prophecy. Adam Brandt thoroughly tested the Hubbert curve in his work. He tested sets of 139 oil extraction curves from local, regional, and national examples to explore the validity of Hubbert's model. The results of his work were, in general, favourable for Hubbert's model [28]. Recently, Patzek and Croft used multi-Hubbert cycle analysis to predict that the peak of global coal extraction is imminent [29]. Ugo Bardi noted that even renewable resources, when extracted beyond their regenerative abilities, tend to have bell-shaped extraction curves. He presented cases of wood extraction in 19th-century Ireland and the recent case of Atlantic $\operatorname{cod}[30]$.

The important conclusion from the Hubbert model is not that non-renewable resources should have symmetrical, bell-shaped curves but that the extraction of resources tends to rise along with a growing economy; however, later this process is reversed when the ultimate limit of scarcity is approached. It is important to note that this occurs only in free-market conditions. In other cases, resource extraction curves can have different shapes, for example under rare political conditions, like those in Russia, where we can see a second peak for the oil extraction curve after the dismantling of the USSR.

To model the non-renewable resource price, we adopt an approach proposed by Reynolds. In his paper, he created a model of resource exploration in which the total reserves of the resource base are unknown during searching for resources and their extraction. His model reveals a specific behavioural pattern in which several years of increasing production simultaneously with lowering prices and costs is followed by a sudden and intense price rise with a significant decrease of production. The availability of technology that can cut costs and increase the reserve base supports a longer increase in production and decline in prices and costs. However, his model suggests that in spite of better technology, we can experience a rapid increase in price as long as the pace of technological innovation is smaller than the growth of demand. He proposed a 'U'-shaped price curve as a model of non-renewable resource price curve development [31].

\subsection{EROEI}

The concept itself has been presented as part of the introduction; some important notes and caveats follow. The Relationship in Equation (1) is seemingly straightforward, but in reality, various studies adopt different system boundaries, which leads to different results obtained for the same fuels, caused by variability in the denominator [2]. The wider the system boundaries selected, the lower EROEI tends to be, as more energy inputs are accounted for. Fortunately, there are efforts to push the common framework for calculations, so this issue should no longer cause confusion.

It is important to note that there are a few important caveats. Studies focused on modern renewables adopting wider boundaries, including even necessary back-ups in the form of batteries to counter intermittency of these energy sources, usually come with much lower EROEI values then presented in the table above. One example study by Ferroni and Hopkirk came to the conclusion that Solar PV is an energy sink based on the analysis of Solar PV installations placed in Switzerland and Germany [32]. Pedro Prieto and Charles Hall also came to a much lower number for solar PV, analysing the comprehensive available data for the case of Spain. According to their conclusion, the EROEI of solar PV installations in Spain is only around 2.45:1 [33,34].

EENGM simulation results depend critically on the EROEI of renewable technology. Hall et al. reported mean values of 18:1 for the EROEI of wind power and 10:1 for solar PV [2]. Pickard noted 
that these estimates have to be downsized dramatically when one considers the systemic EROEI of the whole energy sector composed solely from renewables, as it will need: "(1) a radically strengthened long distance transmission backbone that serves to average generation over continent-sized areas; and (2) an ancillary infrastructure of massive electricity storage to finesse the remaining supply fluctuations inherent to solar-derived electricity" [4]. The study by Weißbach et al. reported a buffered EROEI (accounting for battery storage) of 3.9 for solar PV and 9 for wind power, producing an average of 6.45 [35]. Considering this renewable energy aggregate, we would have to scale down its EROEI further, as solar PV has greater potential for total installed capacity. This consideration still leaves out the reduction necessary to account for the long-distance transmission backbone mentioned by Pickard. Capellán-Peréz et al. reported an EROEI of the whole energy sector running solely on renewable energy sources with a necessary battery backup equal to 3 [36]. For this reason, we ran a model sensitivity analysis predominantly for the EROEI ranging from 3 to 7 or up to 15 in two instances.

Despite these low values reported in the literature, it is important to not forget that technology itself is still evolving. The concept used to show the progression in the development of a certain energy source is the experience curve. The experience curve shows reductions in the price of a unit of installed capacity relative to its cumulative installed capacity. It reflects the learning ratio, which is the reduction achieved in the price of the installed capacity unit per doubling of the installed cumulative capacity. In other words, the experience curve depicts economies of scale without considering other possible influences, for example changes in the prices of the raw materials used in the production of any given renewable energy source. The experience curve for the solar PV price shows a historic learning rate of 22\% in the years 1976-2003. The Renewable Energy Agency reported that, on average, the doubling of the cumulative installed capacity of onshore wind between 1983 and 2014 resulted in a 7\% reduction in the weighted average installed costs [37].

A rising load factor is also reported, which will further contribute to the rising EROEI for onshore wind power (from $20 \%$ in 1983 to $27 \%$ in 2014). This is due to higher hub heights and larger rotor diameters, which helped to increase the load factor despite the fact that, in some countries, lower-quality wind sites were used for the development of new projects [37].

\subsection{Concept of Sustainability Adopted for the EENGM}

Our perception of sustainability or sustainable economic development has to be clarified here, as these concepts have become widely overused and potentially vacuous words. Richard Heinberg postulates five axioms of sustainability [38]. For the model at hand, mainly his second and fourth axioms are crucial, as they are also quantifiable, which is necessary for the model. The second axiom states that population growth and/or growth in the rates of resource consumption cannot be sustained. The fourth builds on the previous one, stating that a sustainable economy has to be closely connected with the declining rate of non-renewable resources usage. Moreover, this rate must be equal to or exceed the rate of depletion. For an economy to be considered sustainable, it must also fulfil the requirements of the remaining three axioms [38].

Aforementioned second and fourth axioms together form model behaviour named sustainability strategy (SUS). Once It is adopted by the model, population growth stops, and all the energy sector investment is redirected to renewable energy generating technology immediately. The model default behaviour is called business as usual (BAU). Populations grow according to the UN predictions, and energy investment is allocated reversely to the energy generating technology prices while $B A U$ is active.

\subsection{Feedback Structure of the Current Models}

The system dynamics paradigm has been proved to be a suitable tool for modelling economic systems. Various models using the framework of system dynamics have been presented in the scientific literature. While the fundamental works were already being published in the 1970s [39] or the 1980s [17], only recent research on simulation methods, tools, and related software applications have enabled 
the development of sophisticated models. The rationale for using the system dynamics method for constructing the EENGM has already been explained by Ref. [22]. Eight of the most relevant feedback structure models $[3,15,17,18,40-42]$ are chronologically ordered and listed in Appendix A-Feedback structure models. The description also contains the main drawbacks and weak points, as the development of the EENGM model is partially based on their mitigation.

\subsection{Description of the EENGM}

The EENGM model builds on the Neoclassical economic model and extends it by the implementation of several blocks or sectors that enable the development of a meaningful energy sector to be used in simulation. Besides the aforementioned typical sectors (technology sector, general-purpose capital goods sector, and population), the production process sector is significantly extended and comprises the influence of energy availability on capital usability in production. Moreover, the endogenous savings rate is included and it is influenced by the total capital amount and the availability of energy resources for its operation. Similarly, the energy sector is elaborated and structured. It comprises a renewable energy source and a non-renewable energy source. The latter is cheap and plentiful at the onset of the simulation. Nevertheless, its price grows due to a decline in its limited reserves. The former is associated with a high price, which decreases with respect to the cumulative installed capacity. The mechanism that divides the investment between two aforementioned energy sources and redistributes energy capital investment is also included. All variables can be found in the file with the model attached to this manuscript as a Supplementary File.

Below, the main variables of the model are summarized. As it is important to comprehend the limitations of the model, selected significant omitted variables are presented:

- Endogenous variables: macroeconomic product, consumption, savings/investment, capital, demand for energy sources, representation of EROEI, extraction and depletion of fossil fuels, renewable energy sources, and the role of energy in the creation of the macroeconomic product.

- Exogenous variables: population, factor productivity and technology.

- Omitted elements: atmosphere, emissions of $\mathrm{CO}_{2}$ and natural resources of a non-energy nature.

The simulation period for the model is 1965-2065. The model recreates behaviour for 50 years (see Figures A1-A3 in Appendix B-Model calibration). This forecast is the main topic of this paper. The assumptions associated with the model are the following:

1. Energy as a necessary production factor-the maximal product potential can be verified in this switch-off state. The product $Q$ is expressed by the energy-dependent Cobb-Douglas production function where $K$ represents the capital stock, $L$ stands for the population stock, and the technological progress is $A$. Energy ( $E_{e t}$ stands for the energy supplied by the energy sector an $E_{r t}$ is the amount of energy needed to fully operate the capital) is needed to use capital stock in production (Equation (2)):

$$
Q_{t}=A_{t}\left(K_{t} \frac{E_{e t}}{E_{r t}}\right)^{\alpha} L_{t}^{\alpha-1}
$$

where $\alpha$ is the capital elasticity in production. Subscript $t$ denotes the explicit time-dependence of the model, which is computed in discrete time steps where each simulation year represents one time step of the model. Structure of the model, basic behaviour, model equations, or model-simplifying assumptions, can be found in Section 2.4 and our previous work [22].

2. An endogenous savings rate-the system can respond to the increased need for investment in the energy sector. There are two types of investment-into general, energy-using capital and into energy sector capital.

$$
I=I_{\mathcal{C}}+I_{e}
$$


where $I_{c}$ corresponds to Capital Investment in the scheme below and $I_{e}$ to Energy Sector Available Investment. The total investment fraction $I_{f}$ is given by

$$
I_{f}=I_{f 0}+M R C / N R C
$$

where $I_{f 0}$ corresponds to Initial Capital Investment Fraction, $M R C$ to Marginal Return on Capital and NRC to Normal Return on Capital. Calibration corresponds to a third Kaldor's fact, in which the capital/output ratio is roughly constant (around two in our case, which corresponds to also to the value reached in DICE model). Investment is then separated into energy and general-purpose capital investment, determined by the Energy Capital Investment Fraction variable. It is the transition function based on the ratio of the Operational Capital/Capital. This corresponds to the total investment dedicated to the energy sector; thus, it is clear that when there is less than $85 \%$ of total capital operated, all investment assets are redirected to the energy sector alone.

3. A starting quantity of the non-renewable source, calibrated to represent the fossil fuels and the uranium ore reserves at the same time (TOE). This represents the stock, from which the energy necessary for production to operate capital stock is extracted. Fossil Fuels Extraction Capital represents the capacity, the amount of resources which can be extracted from available stocks of fossil fuels in 1 year, and it depreciates with a constant rate. The price of fossil fuels, Added TOE capacity price grows with declining amount of Fossil Fuels Reserves. The model uses the following version of the Equation [42]:

$$
F C_{i}=f_{c i}(0) *\left(\frac{R_{i}}{R_{i}(0)}\right)^{\rho}
$$

where $F C_{i}$ is resource price, $R_{i}(0)$ is the initial resource stock, $R_{i}$ stands for current reserves and $\rho$ is the resource coefficient. The model uses the value of -0.78 which corresponds to a six-times higher price than initial this roughly corresponds to historical oil price movements. Reynolds, in his research, concluded that the resource price during the exhaustion phase slowly grows to the levels seen during the start of the extraction [31].

4. The parameter settings for the renewable energy source. The lifetime of the capital used for its generation, the load factor (the percentage of the amount of time when the energy source operates on the level of its maximum performance), and the fall in the cost of capital used for the renewable energy generation by doubling its installed capacity (the so-called learning curve).

5. The initial cost of the renewable energy source (1989\$).

6. Ayres-Warr's hypothesis. When explaining economic growth, the part that cannot be explained by a change in the amount of labour or capital employed in production is automatically attributed to the technological progress, but in fact it is a residual error caused by the exclusion of other variables from the statistical model. The aforementioned authors showed that it was a failure to factor in the useful work, which, in other words, means the increased efficiency of capital in the transformation of energy resources into useful work. By activating this assumption, the exogenous growth of the technological factor is limited in the model. This corresponds to an observation that, in several processes, we are already approaching the thermodynamic limits (e.g., combustion engine efficiency).

\section{Results}

The results are divided between the two aforementioned scenarios, business as usual (BAU) and the sustainability strategy (SUS). Although the EENGM comprises many variables, the development of the gross domestic product, discretionary consumption per capita and investment comprise Figure 2, with fossil fuel extraction and consumption, EROEI development, and total investment rate also being selected to represent the simulation results in the following figures. The values of the other variables can be found in the model itself, which is attached to this study as a Supplementary File. 

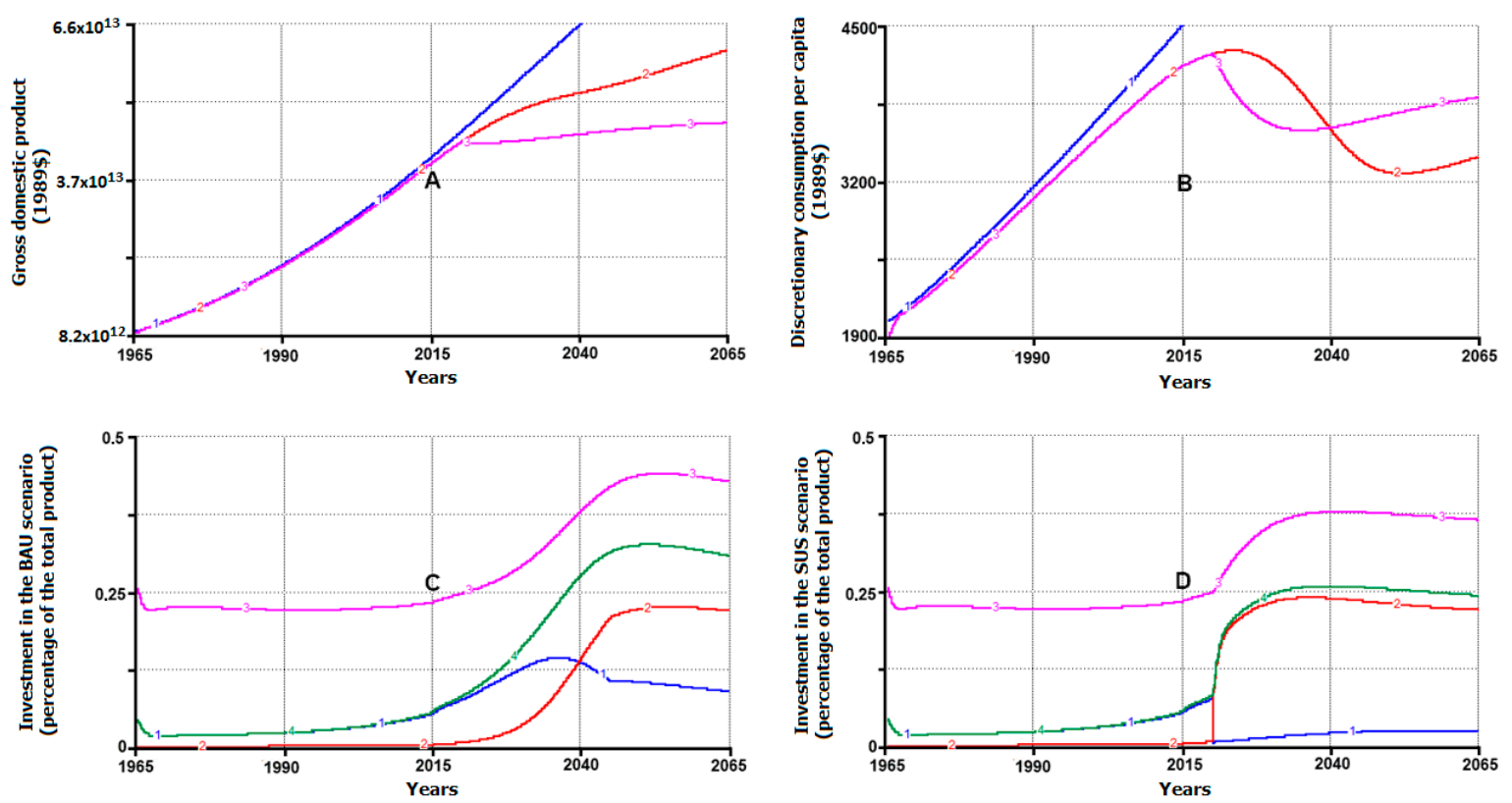

Figure 2. EENGM Simulation results with $\mathrm{EROEI}_{\mathrm{L}}=5$ : $(\mathbf{A})$ - Gross domestic product, 1 - Historical trend, 2-BAU scenario, 3-SUS scenario; (B)-Discretionary consumption per capita, 1-Historical trend, 2-BAU scenario, 3-SUS scenario; (C) - Investment in the BAU scenario, 1-Investment into the fossil fuel capital, 2-Investment into the renewables capital, 3-Total capital investment, 4-Energy capital investment; (D) - Investment in the SUS scenario, 1-Investment into the fossil fuel capital, 2-Investment into the renewables capital, 3-Total capital investment, 4-Energy capital.

The GDP in both scenarios differs sharply from the historical trend line, which can be considered a simple trend extrapolation when the GDP growth is not constrained by energy scarcity and other environmental limits. This is caused in part by the aforementioned saturation of the technological factor and the shift of the investment flow predominantly into the energy sector, which can cause capital shortages in other economic sectors. The worse performance of the SUS scenario is due predominantly to the population being capped at the level of 7.75 billion people, as demanded by the SUS scenario definition, so the small observed GDP growth comes solely from meagre general capital increases. The BAU scenario reaches a much higher total product, but the capital/product ratio falls to 1.54, referring to the higher labour intensity of the product (the average value in the simulation start year is over 1.9; the SUS scenario reaches the value of 1.7), pointing out a significant paradigm shift in the production process relying more on human labour.

The differences in the discretionary consumption are more pronounced than those in the case of the GDP, as both scenarios fail to reach the current levels in the final simulation years. The SUS scenario has slightly higher total cumulative consumption per capita, the main difference being the timing. The adoption of the SUS scenario means lower per-capita consumption in the first two decades of transition but significantly higher consumption towards the end of the simulation period. The observed divergence between the historical trend line and the model's projected consumption in the pre-2018 period is caused by the omission of energy sector investments in the historical trend.

The SUS scenario involves a significantly smaller investment rate than the BAU scenario thanks to the early massive investment in renewable technology at a time when fossil fuels are still relatively cheap. In the later years, the system is confronted with less efficient fossil fuel capital (employed in extracting and processing lower-grade resources, like tar sands and deep-sea oil deposits) and the necessity to invest in immature renewable energy source technology. In the case of the SUS scenario, the investment rate is on the level of $34 \%$ of total GDP, and in the final years of the simulation it declines to $33 \%$, while the BAU scenario reaches the $38 \%$ mark. 
We have elaborated more detailed sensitivity analysis for the expected economic performance of the system. One of the ways in which we can evaluate it is the cumulative per-capita disposable income, being a simple proxy variable for the quality of life. Variables used for this sensitivity analysis were EROEI (in the relatively wide range of 3-15) and a year in which the SUS scenario strategy could be adopted by the system. The results are displayed in Figure 3. The SUS scenario is further varied by population, which is in the first analysis kept constant since 2019 (left side of the Figure 3) as suggested by Heinberg and exactly the same as in the BAU scenario (population growth according to the UN projections) in the second.
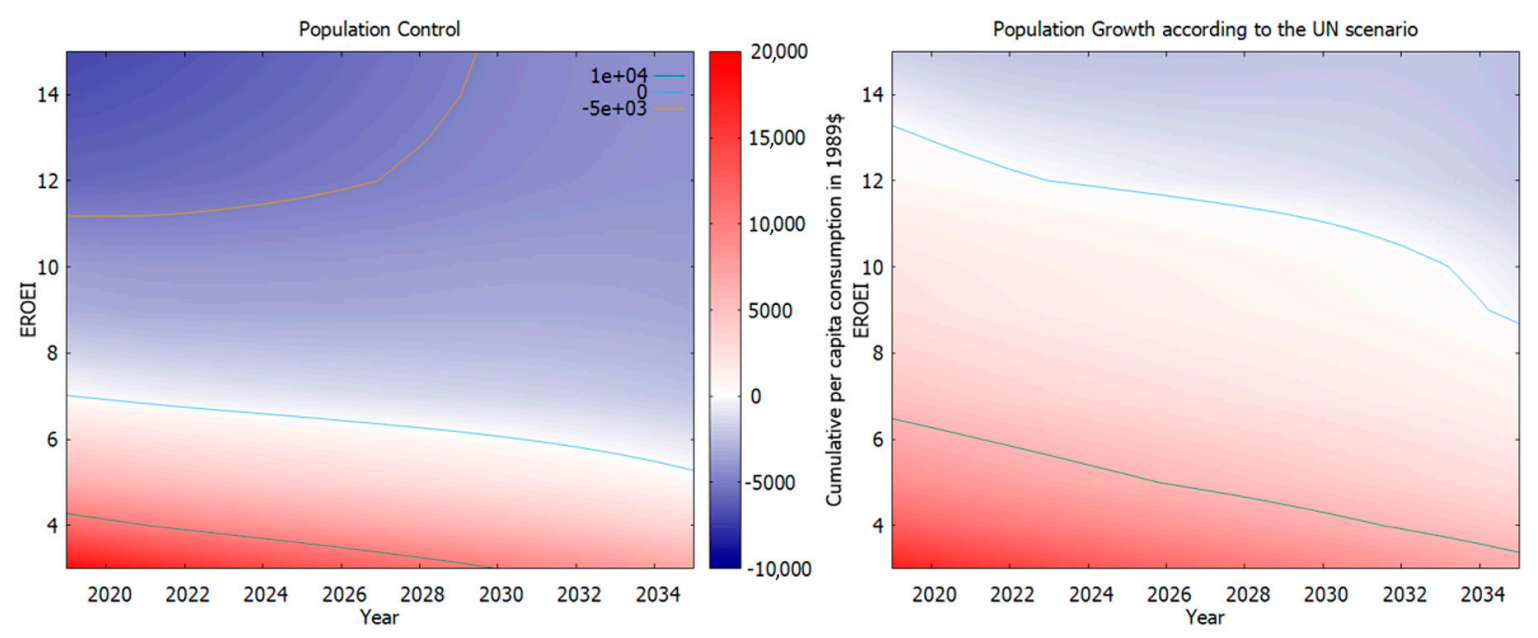

Figure 3. Change of cumulative per-capita consumption in $1989 \$$ between the SUS and BAU development scenarios with varied time and EROEI $_{\mathrm{L}}$. Left side-Population control active in the SUS scenario, Right side - population growth according to the UN in both cases. Negative values represent higher per-capita consumption in the SUS scenario (blue); positive values represent higher per-capita consumption in the BAU scenario (red).

Colours represent different outcomes of the decision to adopt the SUS strategy or do nothing, which corresponds to the BAU scenario. Red colour represents the situation in which it is still economically more advantageous for the system to not change its behaviour/strategy, which produces higher cumulative per-capita consumption. This changes on the level of EROEI 7 and higher, where even early adoption of the SUS development scenario outperforms BAU. There is a saddle point at the $\mathrm{EROEI}_{\mathrm{L}}=9$, where regardless of the SUS year adoption, BAU is outperformed by roughly the same value of per-capita cumulative consumption. In a case of very favourable $\mathrm{EROEI}_{\mathrm{L}}=12-15$, which unfortunately does not correspond to the currently available renewable technology quality (but still might be reachable in the future), the SUS development scenario outperforms BAU by the highest margin if adopted early on.

The SUS development scenario, as defined by Heinberg, demands an immediate cap on population growth. As desirable as it might be from the viewpoint of overall ecosystem degradation, it is not realistic. Therefore, the right half of the chart includes the same analysis, but for the population growing exactly by the same rate like in the BAU scenario. Here we can see that for the majority of values, the BAU scenario performs better than the SUS. This is given by the fact that a system with a constant population does not require the same general-purpose stock capital investments as a growing population does to have its ends meet. This leaves relatively more investment to be allocated for the energy sector accompanied with relatively higher cumulative per-capita consumption at the same time.

It is necessary to point out that in all cases, SUS strategy adoption leads to a better economic performance in the final simulation years. The sacrifices necessary to kick-start transition to renewable energy are significant. The results could change in favour of the SUS development scenario with a longer time horizon. However, even the current model simulation period mightily overcomes the 
typical planning horizon of most governments. So, in this case, even without the use of discounting of future consumption, we are running into a problem that basically, as many noted, the end of the world is free while the will of the people to curb their current income is limited at best.

Figure 4 illustrates the concept of EROEI in the model. The EROEI for the fossil fuel aggregate declines from historically observed values of 100:1 to 4:1, while the EROEI for renewables increases with cumulative investment in technology to the upper level of 5:1.

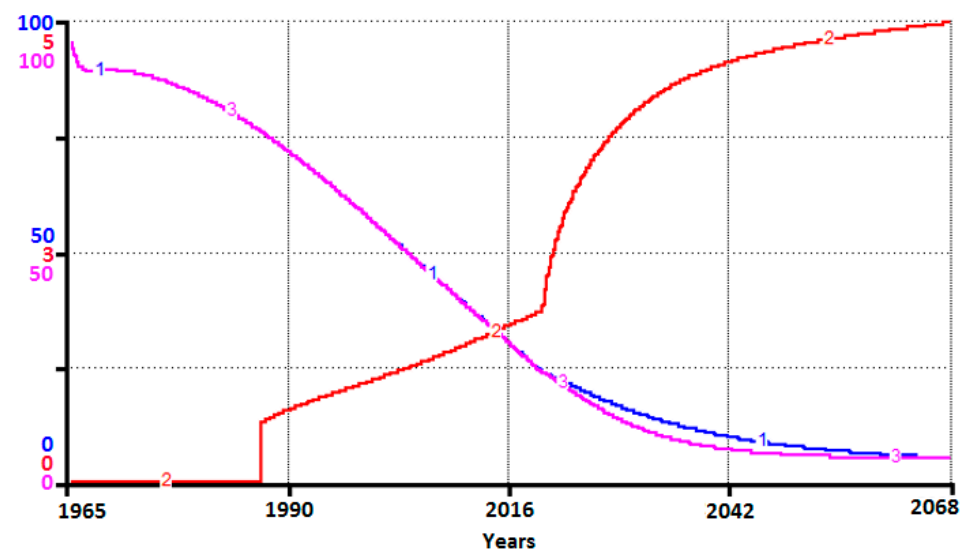

Figure 4. EENGM simulation results for the SUS scenario with $\mathrm{EROEI}_{\mathrm{L}}=5$ : $\mathrm{EROEI}$ development. 1-currently extracted fossil fuel aggregate, 2-newly installed renewable technology, 3-systemic (a combination of the previous two), Y-axis-dimensionless.

It is also important to note that, in the final year of the BAU scenario, renewable energy technology is used to generate $52.6 \%$ of the energy consumed, while, for the SUS scenario, it is $83.4 \%$.

For the model sensitivity analysis (varied EROEI $\mathrm{L}_{\mathrm{L}}$, limit EROEI of renewable energy technology, reachable by newly installed capacity towards the end of simulation), we chose the investment rate fraction, displayed in Figure 5, as it clearly captures the difficulty connected with the energy transition, since only the rest of the GDP can be used for consumption purposes. An investment rate sensitivity analysis was performed for the following renewable resources harnessing capital parameters (see Table 1).
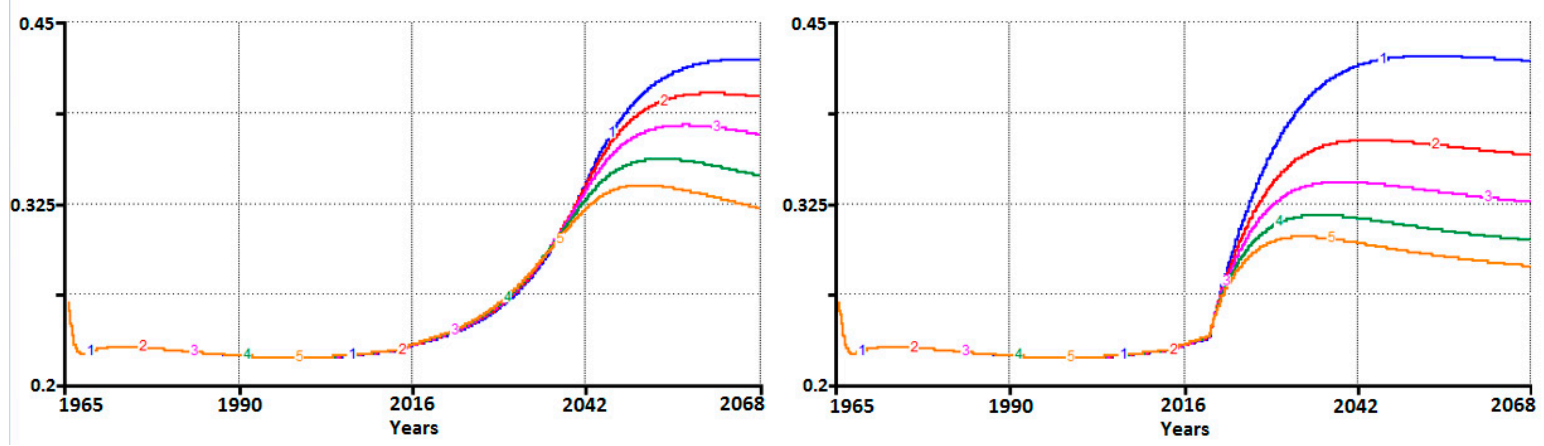

Figure 5. Sensitivity analysis for the total investment rate. Left side-BAU scenario, right side-SUS scenario, Y-axis-a fraction of total gross domestic product (20 to $45 \%$ ). 
Table 1. Renewable resource harnessing capital parameters.

\begin{tabular}{ccccc}
\hline Run Number & $\begin{array}{c}\text { Capital Lifetime } \\
\text { [Years] }\end{array}$ & $\begin{array}{c}\text { Load Factor } \\
\text { [Fraction] }\end{array}$ & $\begin{array}{c}\text { Doubling Constant } \\
\text { [Fraction] }\end{array}$ & EROEI $_{\mathbf{L}}$ \\
\hline 1 & 20 & 0.14 & 0.09 & 3 \\
2 & 20 & 0.16 & 0.11 & 4 \\
3 & 20 & 0.18 & 0.12 & 5 \\
4 & 20 & 0.2 & 0.13 & 6 \\
5 & 20 & 0.21 & 0.14 & 7 \\
\hline
\end{tabular}

It is clearly visible from Figure 5 that, for $\mathrm{EROEI}_{\mathrm{L}}=3$, the investment share is almost equal for the two scenarios, surpassing the $40 \%$ mark. The SUS scenario performs significantly better for the renewable energy technology EROEI of 4 and higher, offering a $4 \%$ smaller investment fraction on average. The SUS scenario thus manages the transition with significantly smaller investment shares, but the economy has to endure them for longer.

Since the EENGM lacks climate representation, it is also important to emphasize that the SUS strategy leads to cumulative fossil fuel consumption of only 746 BTOE compared with 1040 BTOE for the BAU scenario (note: The starting amount of fossil fuels' aggregate reserves is $1280 \mathrm{BTOE}$ ). The price cap is reached in the year 2045 in the case of the BAU scenario, while it is never an issue for the SUS scenario. Figure 6 captures how uncertainty about ultimate recoverable fossil fuels reserve changes the timing of the extraction peak, which is postponed slightly over a decade by the considerable increase in the reserves ( $+25 \%$ added to the initial reserves amount) with a similar change in the price dynamics.
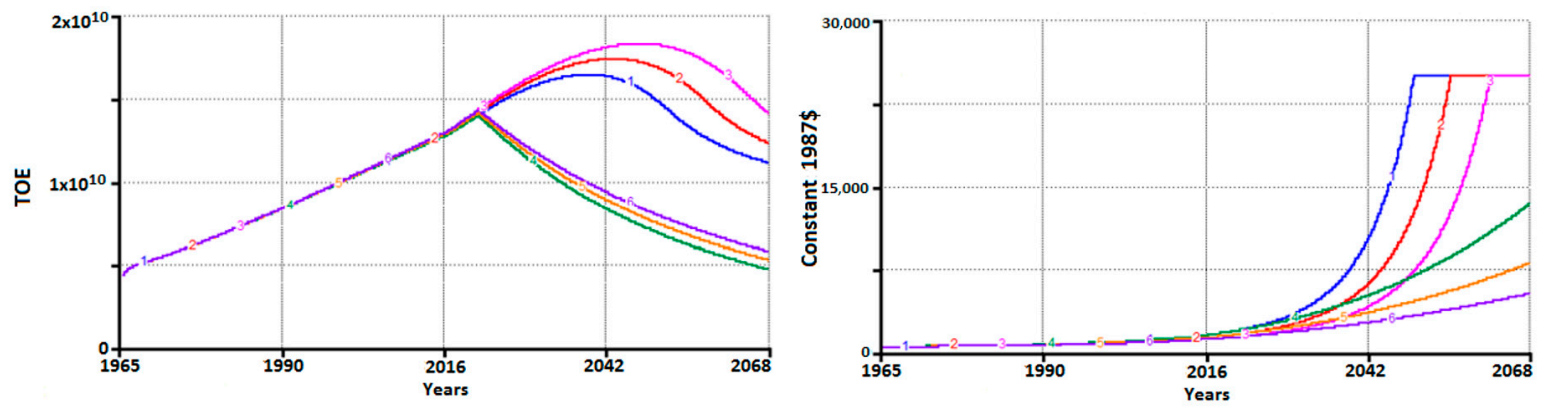

Figure 6. EENGM simulation results with $\mathrm{EROEI}_{\mathrm{L}}=5$. Right chart-fossil fuel extraction, Y-axis—-tonnes of oil equivalent. Left chart-fossil fuel consumption price, Y-axis-price per added TOE of capacity. Run description: 1-BAU scenario with initial fossil fuel reserves $\left(1.2826 \times 10^{12}\right)$, 2-BAU scenario with enlarged fossil fuel reserves (initial reserves $+12.5 \%$ ), 3-BAU scenario with enlarged fossil fuel reserves (initial reserves $+25 \%$ ), 4-SUS scenario with initial fossil fuel reserves $\left(1.2826 \times 10^{12}\right)$, 5-SUS scenario with enlarged fossil fuel reserves (initial reserves $\left.+12.5 \%\right)$, 6 -SUS scenario with enlarged fossil fuel reserves (initial reserves $+25 \%$ ).

Connecting preceding results regarding the investment rate and the absolute amount of used fossil fuels aggregate, we have performed an analysis capturing the feasibility of various model development pathways. For the purpose of the EENGM evaluation, we have defined the Unfeasibility index (UFI) as a sum of the two values. The first corresponds to the maximum energy sector investment rate necessary for certain model development path viability and the second to the amount of fossil fuel aggregate used up during its energy sector operation. The scenario with the highest investment rate observed in the data (which corresponds to $32 \%$ ) for this analysis will receive 1 and if it also has the highest amount of fossil fuel aggregate used (roughly 500 BTOE is used up in 2019 with another 780 BTOE remaining in the ground), it will receive the total UFI $=2$, which is the maximum UFI value. It is important to note that in that case, BAU cumulative emissions are equal to roughly $1220 \mathrm{BTCO}_{2}$, accounting for other $\mathrm{CO}_{2}$ sources (e.g., cement). This can be directly compared with various studies presenting the remaining carbon budget, which we do in the discussion section. The scenario with the 
lowest energy sector investment rate (14\%) and the lowest fossil fuel aggregate used at the same time have the unfeasibility index equal to 0 . Figure 7 shows the result expressed as the reduction of UFI stemming from the SUS development strategy adoption in any given year.

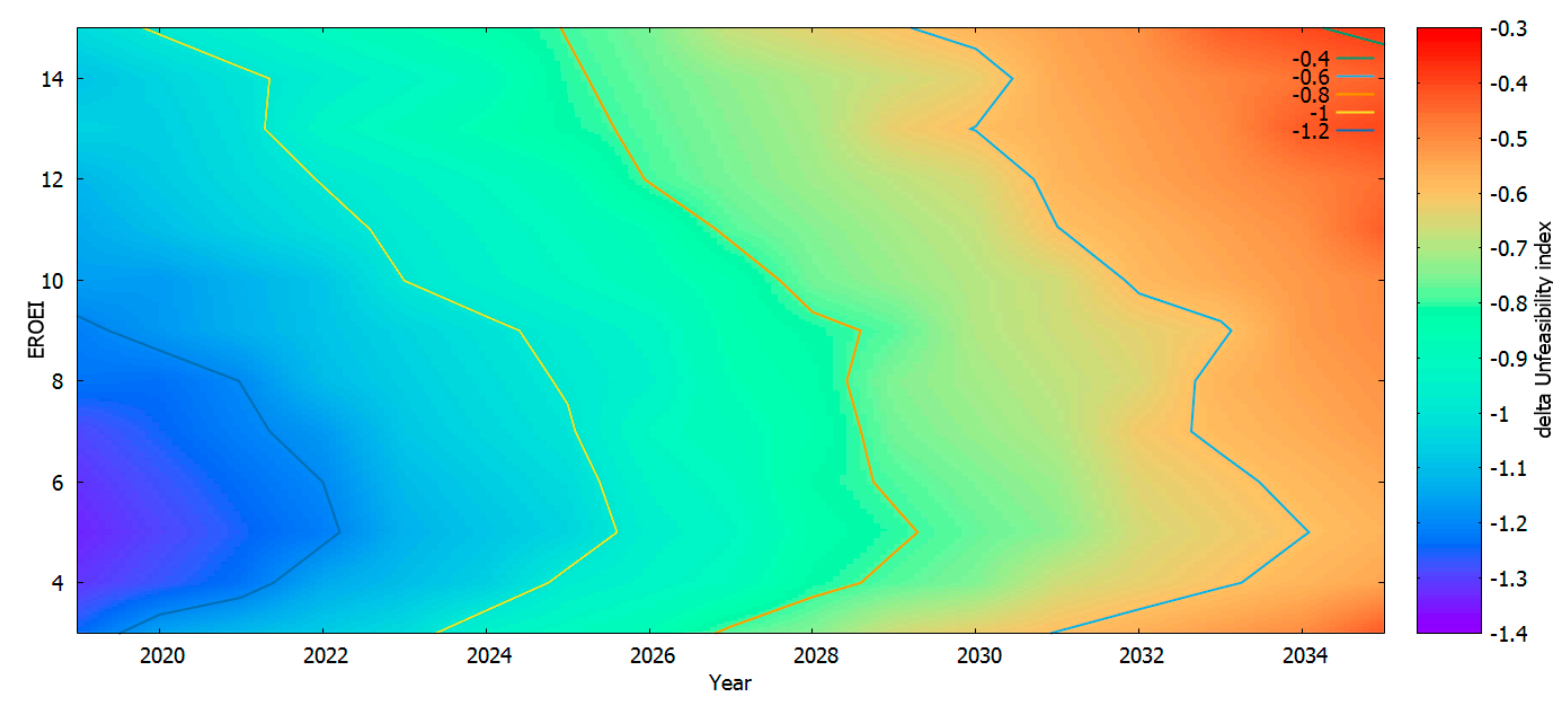

Figure 7. Change of unfeasibility index in comparison between SUS and BAU strategies with varied time and EROEIL. Negative values represent positive development stemming from the SUS adoption in any given year.

It is clearly visible that the highest potential reduction in the feasibility index has the $\mathrm{EROEI}_{\mathrm{L}}=5$, but adoption of the SUS decreases the UFI index significantly at all times. However, with passing time, it is harder and harder to steer the system off from more difficult paths, in which the population has to face an economic squeeze in the form of necessary high investments into the energy sector along with the changing climate, posing a grave threat when combined. The window of opportunity to steer the system off the difficult paths starts to close after the year 2031 for most $E_{R O E I}$ values used in this analysis.

\section{Discussion}

The EENGM is a model developed in the style of the "mind-sized" models. The model is thus relatively well suited to conveying to readers the main qualitative features of energy transition modelling within the common economic framework. The presented novel extension of the Neoclassical model of economic growth created new dynamics in the model where future economic performance is related to the quality of the available energy technology and past investment allocation decisions in the energy sector. Explicit representation of the fossil fuel stock along with the renewable energy technology parameters, installed capacity, and labor stock represent the limitation of the Cobb-Douglas production function. While the substitutability of the factors of production remains, realistic values of the production function parameters are clearly restricted by the stock dynamics in the model, which represent the contribution of the system dynamics approach to economic modelling. EENGM itself turns out to provide results similar to those generated by the more complex models. Its high level of aggregation is thus a drawback and a strong point at the same time. The following discussion starts with the main model limitations.

Various relatively new renewable energy source technologies are aggregated into one with averaged parameters. It is nothing more than a simplistic assumption. The attempts to implement a renewable energy mix in the model were defeated by the fact that, in the real world, investment in renewable energy resources is not driven just by their prices; many other factors are at play. In the case of hydropower, the main factor is usually a political decision about dam placement [42]. Decisions about investment in wind power can be influenced by aesthetical concerns regarding damage to natural 
scenery. The model could not simulate all the various concerns considered during the decision process, and for that reason, there is only one abstract renewable energy source. This, of course, limits the model's significance, as the total EROEI of the whole renewable energy mix will be influenced by its composition. Hydropower has high EROEI values, but it is seriously limited by its total scalability. Wind power has a higher EROEI than solar power but a flattening price learning curve at the same time. All these factors could change the model results and elaborate on the true scale of the economic burden that the energy transition constitutes.

The EENGM omits a few well-known feedbacks. There is no representation of the $\mathrm{CO}_{2}$ emissions and the atmosphere capability of storing carbon and the consequent global warming. This would probably create a need to phase out fossil fuel energy resources faster in the BAU scenario, and it could decrease the GDP growth even further. At least the total quantity of the fossil fuel aggregate is monitored, which gives a certain idea about the total emissions produced. The worst case BAU scenario (EROEIL $=3$ ) produces $1218.75 \mathrm{BTCO}_{2}$ from the energy sector alone, while the best case SUS scenario (immediate SUS strategy adoption, EROEIL $=15$ ) produces $671.25 \mathrm{BTOCO}_{2}$. Rogelj et al. report that the remaining carbon budget is in line with global warming not exceeding $1.5^{\circ} \mathrm{C}$, compared to the preindustrial levels which are around $600 \mathrm{BTCO}_{2}$ [43]. Since the model does not account for other sources of $\mathrm{CO}_{2}$ outside of the energy sector, even an extremely radical program, which the SUS strategy indeed is, fails to remain within this carbon budget by a wide margin.

Another omitted feedback is represented by the need to replace the energy end-use capital stock, which is responsible for the production of the economic goods. This need could arise in the case of a fast fossil fuel phase-out or as an inevitability in the case of a rapidly declining fossil fuel extraction curve. Grubler emphasized the importance of energy end-use capital stock for energy transition. This capital stock is many times bigger than the energy-generating capital stock, so its role in energy transition could be considerable, as it might be necessary to change its composition alongside the changing energy-generating capital. It means that lock-in of the energy supply may be created by the energy-using equipment stock. Grubler further presented a figure for the total global annual energy investment, which amounts to US\$0.3-3.5 trillion and surpasses the energy supply side investment of US $\$ 0.7$ to 1.0 trillion (annual figures in 2005 constant dollars) [44]. The inclusion of this feedback could influence the model results negatively, as the amount of investment needed in various scenarios could rise significantly, thus making those scenarios unfeasible.

Lastly, Population is an exogenous variable in the model, based on the UN population predictions. It is clear that in a case when only the low EROEI $\left(\right.$ EROEI $\left._{\mathrm{L}}=3-5\right)$ technology is available, per-capita energy consumption will drop to very low levels towards the end of the EENGM simulation period. Smil presented the relationship between per capita energy availability and infant mortality rate, the average per capita food availability and life expectancy at birth, with all three variables increasing and growing in a non-linear fashion with the energy consumption [9]. Population levels in certain model scenarios could be adversely affected with this feedback present in the model.

To summarize, the above-presented omitted variables and missing feedbacks together could significantly influence the model results adversely; its results can thus be viewed as best-case scenarios.

The comparison with other models is not straightforward, as they usually employ different sets of assumptions. Compared with the standard run of the legendary limits to the growth model, the model results are a little more optimistic. The LTG model's industrial output and services per capita peaked and declined shortly before the year 2020 [45]. The current model does not predict a decline in per-capita discretionary consumption before the year 2029 for the BAU scenario. In the SUS scenario, the peak in per-capita consumption is immediate, but, during the final years of the simulation, it returns close to the peak levels. The LTG considered a more comprehensive set of environmental feedback but suffered from an even greater aggregation of the main variables.

In the MEDEAS model, the global economy falls into a lasting recession shortly after 2025 and the per-capita GDP levels drop below the levels obtained in 1995; results that are relatively similar to those obtained by the EENGM simulation. In both scenarios simulated in the MEDEAS model, the 
per-capita GDP falls below 5000 constant 1995\$, while in the EENGM it stays above 6000 constant 1989 . Unfortunately, the investment and consumption shares in the GDP are not reported, so the comparison is narrowed to these two variables. We also consider the per-capita GDP to be a poor indicator of affluence, as the investment share in the GDP is expected to rise considerably during the energy transition. It seems that the MEDEAS results point out even greater economic hardship to be expected during the energy transition. This difference can also account for the lower EROEI of 3 used by the authors [46].

A similar approach was selected recently also by Victor et al. to develop their EETRAP model. EETRAP is a mathematical model with a macroeconomic framework which is used for building the EROI metric and the energy characteristics of renewable generation. EETRAP was used for simulation analysis to test how renewable investment will be affected by varied EROI of renewables. Authors conclude that the renewable investment rate by 2050 is significantly larger than the current energy investment rate and crowds out investment into general purpose capital and can cause a prolonged recession.

In comparison with the EENGM, our results are significantly worse in terms of the size of the investment rate. In the worst-case scenario of the EETRAP model, the investment rate for renewables peaks at $17 \%$, while the authors used the energy system EROEI of 3 (slowly declining to this value with increasing penetration of renewables) [47]. In the EENGM, the investment rate for renewables plateaus at the level of $32 \%$ (with $\mathrm{EROEI}_{\mathrm{L}}=3$ ) in the BAU scenario and $27 \%$ for the SUS scenario. Unfortunately, the overall investment, and thus also the savings rate, is not reported for the EETRAP; a direct comparison is therefore impossible. The difference between the EENGM and the EETRAP lies at least partly in the more aggressive pricing function for the non-renewable resource extraction capital (capped at 25,000 1989\$ per added TOE of incremental extraction capacity).

After seeing all the EENGM results, knowing its inherent limitations, what course of action does it suggest? One of the model lessons is that the price signals (for non-renewable resources) should not be trusted, or used solely as the primary decision factor guiding energy policy while being compared with the alternative technologies. When used in this way in the EENGM BAU scenario, investment into renewable energy technology is postponed for too long, creating a situation with a very high energy sector investment rate (assuming the lower renewable energy technology EROEI values, which are in accord with currently reported values in the literature $[35,46])$. This is in line with previous work of Reynolds and Hirsch [31,48]. In reality, we should also account for the feedback between supply and demand, which could create oscillations in the resource price when the excessively high price could temporarily decrease demand. The EROEI of a given technology in question and its probable trajectory should have higher weight than price alone. It is clear that the development of high EROEI renewable energy technology should have maximum support; otherwise we can expect steadily declining standards of living, measured as per-capita consumption (without even accounting for decreasing utility of further degrading natural environment). Unfortunately, no amount of investment guarantees the actual existence of the high-EROEI technology, without which considerable economic adjustments are unavoidable.

Further research could focus mainly on model extensions to include the previously identified omitted feedback and their consequences for model dynamics. Energy resources could be disaggregated to individual fuels, for example, coal, oil, and natural gas in the case of fossil fuels and hydropower, wind power, and solar power in the case of renewables. A second step should follow-making the energy end-use capital dependent on a certain composition of the energy mix. With the rapidly changing energy mix, energy end-use capital also has to be replaced faster to be able to use the new energy mix composition. Since every energy source has a different $\mathrm{CO}_{2}$ emission profile, the model should also be extended with a module containing various atmospheric stocks and flows to represent $\mathrm{CO}_{2}$ accumulation and consecutive temperature and weather changes with associated possible disruption to the economic process in the form of a damage function. 


\section{Conclusions}

The representative model of economic development was selected and translated into the system dynamics format; its extension with the complete energy sector containing renewable energy sources, the demand for energy sources and the stock of fossil fuels, was demonstrated. Another improvement is the energy-dependent production function, in which capital usability depends on the energy available for its operation.

The extension of the model resulted in a new behaviour in which a shortage of energy leads to a smaller amount of capital available for production. This increases the savings rate and investment available for the energy sector. However, the smaller general-purpose capital stock leads to lower GDP growth, and the higher savings rate limits discretionary consumption. The GDP itself becomes "obsolete", as it does not capture the rising ineffectivity of the system caused by the underperforming energy sector scrambling for the last remnants of fossil fuels with a rising stock of low-EROEI intermittent renewables. In both model scenarios, the GDP grows along with the declining per-capita consumption.

To put the results obtained in the current model simulations into perspective, at the peak of the war effort, the US economy was able to devote over $40 \%$ of its output solely to defence spending [49]. Johnson [50] reported that the share of household consumption in Nazi Germany shrank to $33 \%$ of the output in 1943. The EENGM thus portrays the future in which the share of consumption in the GDP in an economy undergoing energy transition can approach levels only seen in the totally war-oriented economies, a notable difference being the fact that the large investment share needs to be maintained not for a few years but for decades (an important caveat is the fact that it still means many times higher per-capita consumption in constant currency when we directly compare that to the WWII period).

Supplementary Materials: The following are available online at http://www.mdpi.com/2071-1050/11/13/3644/s1, File S1: Simulation model.

Author Contributions: Conceptualization, L.R.; methodology, L.R. and V.B., validation, L.R. and V.B.; resources, L.R.; data curation, L.R.; writing—original draft preparation, L.R. and V.B.; visualization, L.R.

Funding: This research received no external funding.

Acknowledgments: Authors would like to thank for the support from the FIM UHK excellence projects for the year 2019.

Conflicts of Interest: The authors declare no conflict of interest.

\section{Appendix A. Feedback Structure Models}

\section{Appendix A.1. The Energy Transition and the Economy: A System Dynamics Approach}

The purpose of John Sterman's work was to develop an integrating framework to evaluate the effects of depletion of non-renewable energy resources and rising energy prices on economic growth, inflation and other key economic and energy indicators. For that purpose, he created the system dynamics model of the U.S. economy which provided a general disequilibrium representation of the major linkages between the energy sector and the economy. GNP, consumption, investment, wages and prices and other economic and energy variables were determined endogenously by the model [17].

Analysing the model, Sterman concluded that the depletion of energy resources will cause a rise of real energy prices along with increased capital requirements in the energy sector and that these depletion effects will be amplified by feedback mechanisms in the economy, further worsening economic performance. Delays in substitution and the development of new energy sources were expected to further exacerbate the impact of depletion. The magnitude of the economic effects was found to be substantial, including reductions in economic growth and even reductions in the absolute value of GNP [17].

The model itself is indeed a case of seminal work, although it is not free of major drawbacks, as the author himself pointed out. One recognized problem is the size of the model (over 250 state variables) which obstructs its deeper analysis and potentially hinders the understanding of its behaviour in 
simulation and applied policy analysis. Another problem is connected to the assumed backstop energy technologies or unconventional energy sources. No depletion effects or resource constraints are assumed in their case and long run costs are stable, environmental constraints are also non-existent. None of these are true. The current understanding of the limits of unconventional energy sources like oil sands or renewable energy sources in general has advanced in the last decade.

\section{Appendix A.2. Dynamic Integrated Model of Climate and the Economy (DICE)}

According to its author, William Nordhaus, DICE is [51]: “ . . a simplified analytical and empirical model that represents the economics, policy, and scientific aspects of climate change". The DICE model views the economics of climate change from the perspective of neoclassical economic growth theory, adopting the Solow-Swan growth model. That means that economic output is represented by a Cobb-Douglas production function which uses physical capital, technology factor and labour as inputs. Total global population is assumed to be the available labour force and it grows exogenously over time. The technological factor, or technology level (otherwise known as total factor productivity) also increases exogenously over time. The DICE model includes the "natural capital" of the climate system; it views the concentrations of greenhouse gases as negative natural capital, and emissions reductions as investments that raise the quantity of natural capital (or reduce the negative capital). In each simulated period, a part of output is lost according to a climate change damage function; the rest is then divided between consumption, investment (savings) and expenditures on emissions reductions. Expenditures used to limit harmful emissions reduce current consumption, but prevent economically harmful climate change in the future, enhancing consumption possibilities in later periods [51,52].

The model results indicate that even uncontrolled climate change is not highly problematic at all. In the base case scenario, which is equal to almost no policies aimed at reducing GHG's and in which temperature rises to $4{ }^{\circ} \mathrm{C}$ above the year 1900 levels, global output is equal to 511 trillion U.S. dollars, while the output in the scenario-limiting temperature rise to $2{ }^{\circ} \mathrm{C}$ is equal to 515 trillion U.S. dollars (both values for the year 2100), a negligible difference [51].

\section{Appendix A.3. Feedback Rich Energy Economy Model (FREE)}

Fiddaman's research builds on earlier system dynamics models of energy economy interactions (e.g., previously introduced model developed by John Sterman, and DICE model), creating a model that tests the implications of a number of feedback processes that have not been previously explored in the climate change context. Among these were [15]:

- a disequilibrium energy-economy system, with adjustment and perception delays, embodiment of energy requirements in capital, and resource depletion;

- inclusion of endogenous technological change and other positive feedback effects which may lead to lock-in of the energy-economy system to particular supply and end-use technologies, explicit behavioural rules, rather than myopic or intertemporal optimization, for decision making;

- separation of the search for optimal social policies from savings, factor allocation, and other decisions; and

- an equitable approach to the valuation of impacts across time.

The main purpose of the model was to identify the policy implications of the previously presented structures, so policy makers may become aware of blind spots in previous analyses [15].

The major feature that differentiates the production structure of the FREE model from others is that energy requirements are embodied in the capital stock itself. Once capital is constructed, it is not possible to improve its energy intensity significantly. This reflects the fact that, in the real world, energy consumption depends on the energy requirements of durable products like automobiles, machinery, and homes [15].

$$
Y(t)=A \Omega_{(t)} K_{(t)}^{\gamma}\left(L_{(t)}{ }^{d_{(t)}} E_{(t)}(1-d(t))\right)^{(1-\gamma)}
$$


where $Y$ is output, $A$ is technology, $\Omega$ represents climate effects, $K$ is capital, $L$ is labor, $d$ is labor rate, and $\gamma$ stands for capital share.

One of the problems of the model is insufficient representation of the resource depletion process, as the author himself noted [15]: "At the time of model conceptualization, the depletion issue was not expected to be as dramatic as it later proved to be. The depletion issue needs to be re-examined. A central part of this effort should be the development of a resource valuation process founded on observations of real behaviour rather than on principles of optimal control".

\section{Appendix A.4. Resource Exergy Services Model (REXS)}

The REXS model simulates economic growth of the U.S. through the 20th century and extrapolates the simulation for several decades into the next century. The REXS model differs from previous energy-economy models such as DICE by eliminating the assumption of exogenously-driven exponential growth. Instead, authors suggest a simple model representing the dynamics of technological change in terms of decreasing energy (exergy) intensity of GDP and endogenously increasing the efficiency of conversion of raw material and fuel inputs (exergy) to primary exergy services ('useful work'). The traditional assumption of exogenous technological progress increasing at a constant rate is replaced by two learning processes based on cumulative economic output and the cumulative energy (exergy) service (useful work) production experience [18].

The authors adopt an alternative view of technological progress which grows according to a different covering law, namely the law of constrained growth. Authors agree that knowledge creation is endogenous, but they also argue that knowledge, as applied to the production processes, is not homogeneous or fungible, nor does it grow without limit. In particular, they conceive technical progress as the increasing time trend of value added to raw materials, which is the sum total of process-chains, aggregated over the whole economy. They then focus solely on the impact of accumulating knowledge as applied specifically to aggregated materials conversion processes in the economy. They suggest that exergy conversion efficiency is a plausible and quantifiable surrogate for knowledge accumulation [18].

The generic form of the production function is $Y=f(K, L, U)$, where $Y$ is output; $K$ is industry capital; $L$ is labour; and $U$ is exergy services (Exa Joules).

$$
y=u \exp \left[a\left(\left(2-\left(\frac{l-u}{k}\right)\right)\right)+a b\left(\frac{l}{u}-1\right)\right]
$$

where the previously unmentioned variables are parameters $a, b$ are constant parameters. The authors developed two forecasts using this model. The first one involved varying the future rate of decline of the energy intensity of output from $1.2 \%$ (business-as-usual) to $1.5 \%$ (significant efforts to dematerialize) over the period 2000-2050. The corresponding forecasts of GDP are following: In the business-as-usual case (intensity decline rate of 1.2\%), output doubles from the 1998 level. The corresponding flows of natural resource exergy are forecast to increase by 50\% over 1998 levels. For the more rapid rates of energy intensity decline of 1.4 and $1.5 \%$, economic slowdown and even shrinkage are forecasted.

The revolutionary approach of the model to the economic growth is spoiled because it ignores resource stocks, violating the paradigm of good system dynamics modelling practices. The model unrealistically assumes that there are always enough readily available energy resources at hand to be used in the economic process. The second problem is that authors claim that the model is better because it does not explain economic growth on the basis of exponentially growing technological factors, yet the rate of energy intensity decline of the output is also exogenously-driven, so the advancement consists only of factor identification.

\section{Appendix A.5. Energy Sector for the Integrated System Dynamics Model for Analysing Behaviour of the} Social-Economic-Climatic Model

Simonovic and Davies describe their model as five interconnected components which constitute the full energy sector: demand, resources, economics, production, and emissions [42]. Resource stocks 
are well represented for each fossil fuel source, and the extraction prices rise with declining reserves according to this Equation:

$$
F C_{i}=f c_{i}(0) \times\left(\frac{R_{i}}{R_{i}(0)}\right)^{p}
$$

where $f c_{i}(0)$ is the initial resource price, $R_{i}$ and $R_{i}(0)$ are the current and initial resource reserve, and $p$ is the resource coefficient set to -0.4 [42]. Energy demand in the model is defined in the following way:

$$
E D(t)=r_{E D: G D P_{1990}} \times Q(t) \times \operatorname{SMOOTH}\left(\left[\frac{A E P}{A E P_{1990}}\right]^{p}, 10\right)
$$

where $E D$ is energy demand, $r_{E D: G D P_{1990}}$ is the ratio of energy use to GDP, $Q$ is the macroeconomic product, $S M O O T H()$ is a Vensim function that averages the left hand argument over a specified period, $A E P$ is the average energy price, and $A E P_{1990}$ is the starting energy price [42]. $Q$ is a result of an unmodified Cobb-Douglas production function and the necessary energy investment is prescribed as thus always satisfied. The problem with this approach is that there is no feedback from the energy sector to the economic sector. In other words, $Q$ can rise indefinitely, regardless of what happens with the energy sector output. This is utterly unrealistic, according to the previous section reviewing current empirical literature focused on the problem.

The model also lacks more elaborated representation of the renewable energy sources. There is only hydropower and other renewable energy sources, without further specifications of their parameters (other renewables). In this form, the model cannot meaningfully model energy transition. The authors probably intended to use this model to improve their previous model encompassing climate and water sub models and their development till the year 2100. Unfortunately, while the model in this form might meaningfully represent past system behaviour as the authors note, it cannot realistically provide future possible scenarios of development, moreover in such a long period. We were not able to verify that authors actually used (horizontally integrated it into bigger model, which authors call ANEMI: a new model for integrated assessment of global change) this model in their later modelling as they did not mention the energy sector explicitly $[53,54]$.

\section{Appendix A.6. World Limits (WOLIM) and MEDEAS Models}

WOLIM is described as an Economy-Energy-Environment model based on System Dynamics which integrates the following aspects: the physical restrictions (with peak estimations for oil, gas, coal and uranium), the techno-sustainable potential of renewable energy estimated by a novel top-down methodology, the socio-economic energy demands, the development of alternative technologies, and the net $\mathrm{CO}_{2}$ emissions [41].

The authors themselves note that the model is not as feedback-rich as SD models tend to be, e.g., it does not incorporate feedback from the energy sector to the economy-increased energy scarcity and a lack of fuels for capital goods does not reduce economic growth. Among exogenous variables of the model, we can find GDP growth, non-renewable resources extraction curves and renewable energy sources installations [41].

Energy demand $E_{i}$ calculation is simple:

$$
E_{i}=G D P \times I_{i}
$$

where GDP is an exogenously-generated time series and $I_{i}$ is the energy intensity of a given sector (model considers three sectors, transport, electric, and industrial buildings sector). Energy intensities are exogenously decreasing based on past trends and differences between various scenarios, according to the assumptions considered for them by the authors [41].

Exogenous variables are grouped into scenarios, according to different sets of assumptions. During the model simulation, the feasibility of any given scenario is determined by the difference between energy demand and energy supplied. If there is a gap bigger than $5 \%$ of energy demand, 
then the scenario is considered to be unrealistic. Energy shortages appear in the model soonest in the transportation sector (in all scenarios before 2020) and before 2030 for total primary energy production [41].

The model is still being developed, now under the new name MEDEAS. Focus is put on the development of the previously missing supply constraint which feeds back to the economy throughout the energy availability via an input-output table for 35 economic sectors. Other economic feedbacks, i.e., the crowding out effect of the investment into the energy sector onto the investment into other economic sectors is still being worked on [46].

\section{Appendix A.7. Sustainable Energy Transition Model (SET)}

Sgouridis et al. [3] developed this model as a tool to assist planning towards a sustainable energy transition. It is a net-energy-based model that quantifies the energy transition trajectory, i.e., the rates at which society should install renewable energy in purely physical terms. The renewable energy installation rate is in their model fully determined by four factors: the net energy demand over time, the carbon emissions limits, the profile of the fossil fuel phase-out, and the renewable energy technology characteristics-especially its EROEI. Using this model, a range of possible transition trajectories are mapped and their relative desirability is assessed. The trajectory selected as desirable can then serve as a clear mechanism for setting renewable energy policy targets.

The SET model is unique in its consideration of EROEI for fossil fuels. The net primary power $\left(P F_{\text {net }}(t)\right)$ of the resource has a declining average EROEI $R_{f}(t)$ through a combination of the increase in technological efficiency and the decrease in the quality of the remaining resource. Net primary power can be written in relation to EROEI as [55]:

$$
P F_{n e t}(t)=P F(t) \frac{R_{f}(t)-1}{R_{f}(t)}
$$

Another unique feature of the model is its detailed representation of renewable energy resources. Authors assume an increasing EROEI due to a learning curve effect, determined by total cumulative installed capacity [55].

The energy economy subsystem is different than in other models, there is no Cobb-Douglas production function nor its variant used in the mode. The authors adopt a different approach. The energy is provided by the renewable and non-renewable resource subsystems. This energy is not fully available to society as a portion must be reinvested in building renewable and non-renewable energy ( $I$ ) generation infrastructure, with the remainder being available for societal needs-e.g., agriculture, non-energy manufacturing, and services (net social surplus- $-P S_{\text {net }}$ ).

$$
P S_{\text {net }}(t)=P F_{\text {net }}(t)+P R(t)-I(t)
$$

Authors then form three constrains which have to be fulfilled in order for energy transition to be successful [3]:

- the impacts from energy use during SET should not exceed the long-run ecosystem;

- carrying and assimilation capacity;

- per-capita net available energy should remain above a level that satisfies societal needs at any point during SET and without disruptive discontinuities in its rate of change;

- the rate of investment in building renewable energy harvesting and utilization of capital stock should be sufficient to create a sustainable energy supply basis without exhausting the non-renewable safely recoverable resources. 


\section{Appendix A.8. WEM (World Energy Model)}

WEM is based on the World 3 model used in one of the iterations of the original Limits to Growth study. The main modification of the original model is the replacement of generalized resource and pollution variables with specific energy and climate change factors. According to the authors, main model variables are population, industrial capital, food production, energy production, and global warming. The model was developed with the usage of SW STELLA and its scenarios are simulated until 2100 [40].

For the energy sector, authors developed the submodel implemented in excel, which projects the average energy costs and GHG emissions. These variables are therefore given and de-facto exogenous for the rest of the model. According to its results, energy costs approximately double through the 21st century. The authors themselves acknowledge that it is a main shortcoming of their model: "... the quantitative results from WEM are dependent on the relatively arbitrary assumptions made concerning future energy prices." [40]

WEM-generated scenarios suggest that industrial output will continue its growth up to the year 2100 in all scenarios while global temperature rises to $2.7^{\circ} \mathrm{C}$ at worst. The trend in the industrial output was not reversed even when the authors prolonged the simulation period up to the year 2150 . WEM results are thus much more optimistic than the original results of Limits to Growth study, where industrial output collapsed well before 2100 in most scenarios [40].

In conclusion, the authors state that: "The key and relatively unique strengths of WEM are its global scope, extended timeline, and system dynamics methodology." [40] Unfortunately, important feedbacks are omitted, as the price of the energy aggregate is not dependent on industrial output but on time, which is not in accordance with good system dynamics modelling practice. Model behaviour is driven predominantly by one exogenous variable and generated internally by the model. Furthermore, the absence of a meaningful GDP measure along with the investment makes the model results hard to interpret.

\section{Appendix B. Model Calibration}

Short overview of the model calibration for the few basic variables. The model is able to recreate historical development of the selected variables reasonably well. An explanation of the short-term fluctuations (e.g., oil embargoes) cannot be reasonably expected.

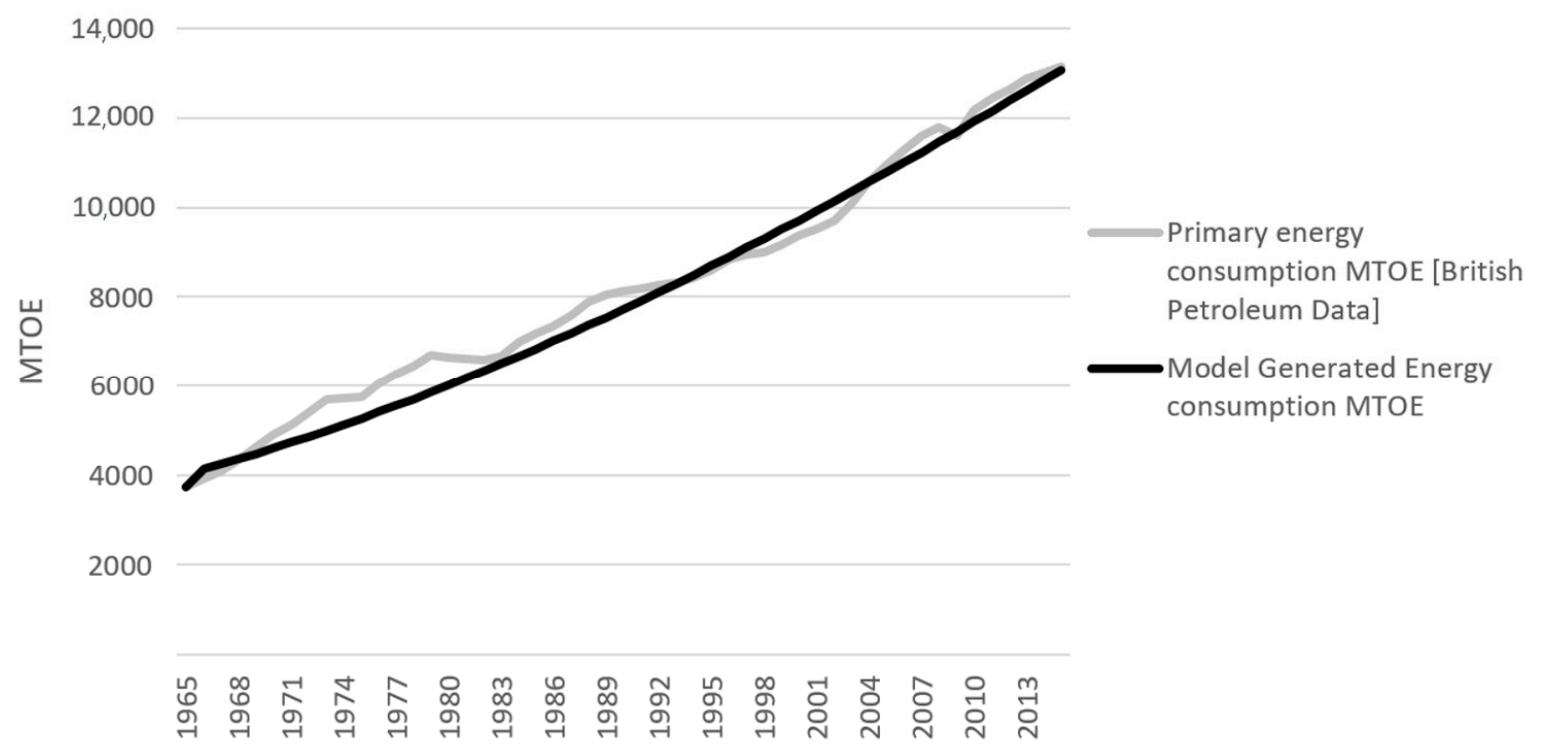

Figure A1. Primary energy consumption, real world vs. model generated. Source: own work. 


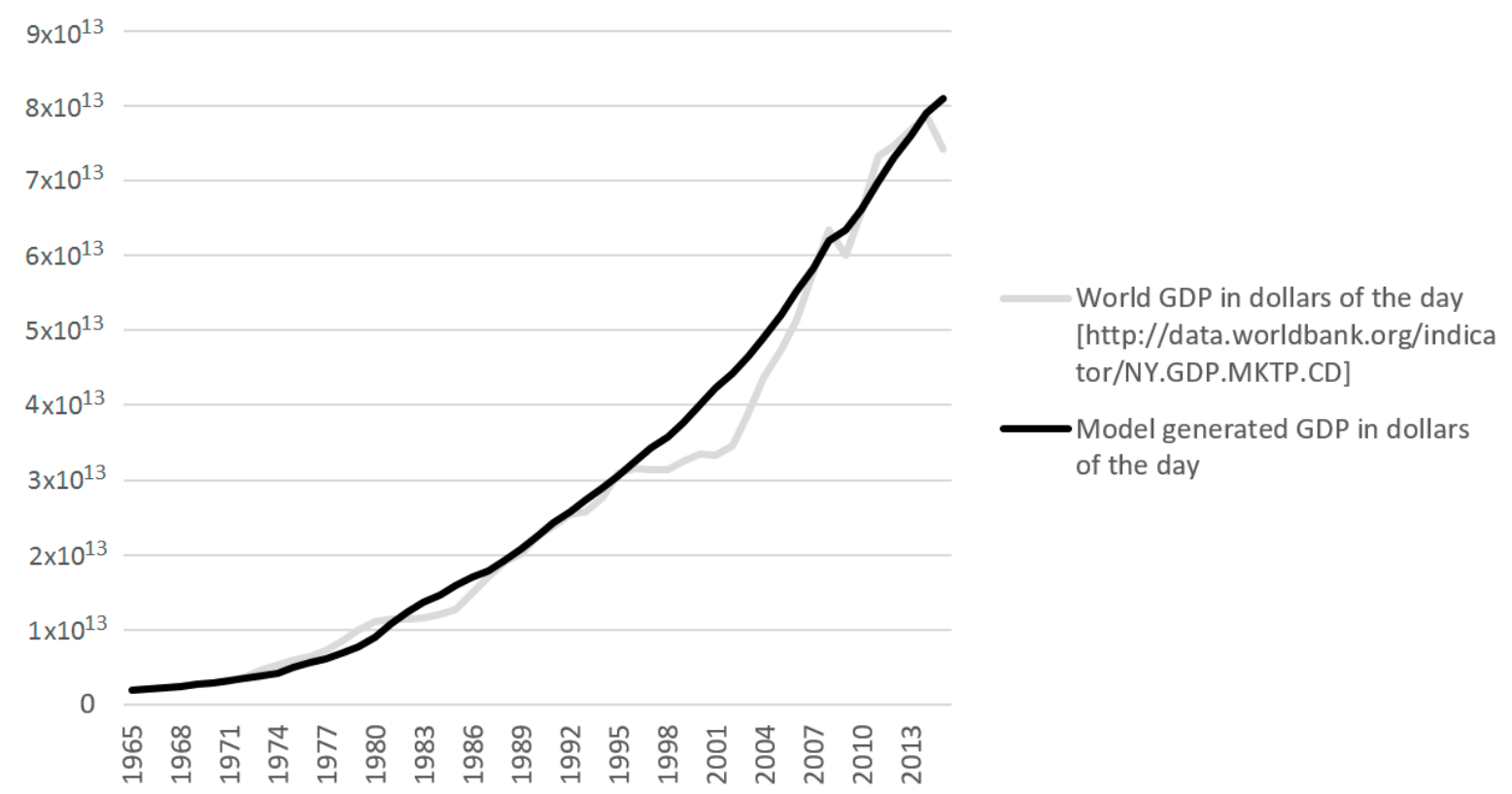

Figure A2. World GDP, real world vs. model generated. Y axis—dollar of the day. Source: own work.

2.5

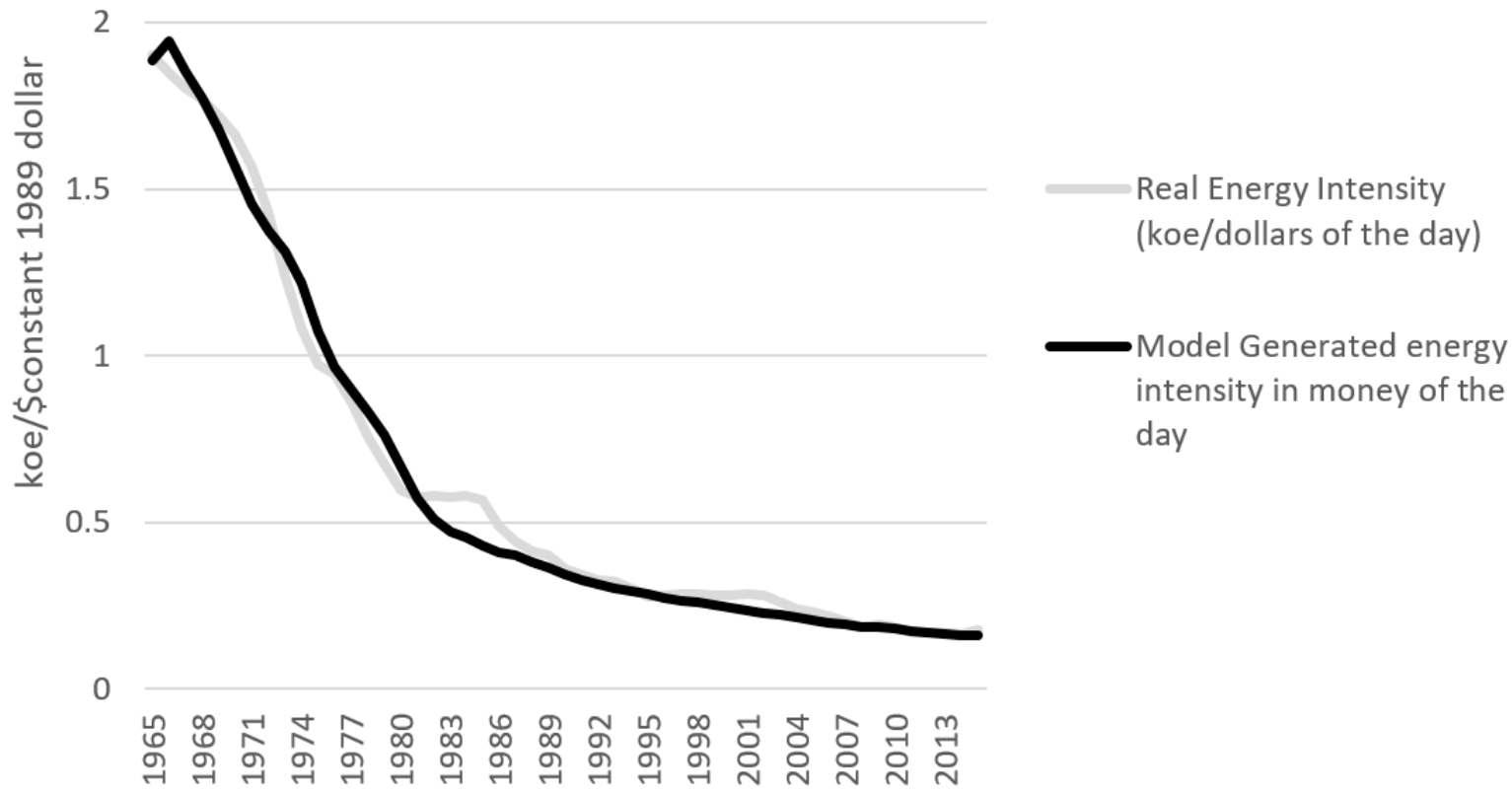

Figure A3. Energy intensity of product, real world vs. model generated. Source: own work.

\section{References}

1. Murphy, D.J.; Hall, C.A.S. Year in review-EROI or energy return on (energy) invested. Ann. N. Y. Acad. Sci. 2010, 1185, 102-118. [CrossRef] [PubMed]

2. Hall, C.A.S.; Lambert, J.G.; Balogh, S.B. EROI of different fuels and the implications for society. Energy Policy 2014, 64, 141-152. [CrossRef]

3. Sgouridis, S.; Csala, D.; Bardi, U. The sower's way: Quantifying the narrowing net-energy pathways to a global energy transition. Environ. Res. Lett. 2016, 11, 9. [CrossRef] 
4. Pickard, W.F. Energy return on energy invested (EROI): A quintessential but possibly inadequate metric for sustainability in a solar-powered world? Proc. IEEE 2014, 102, 1118-1122. [CrossRef]

5. Warr, B.; Ayres, R. REXS: A forecasting model for assessing the impact of natural resource consumption and technological change on economic growth. Struct. Chang. Econ. Dyn. 2006, 17, 329-378. [CrossRef]

6. Court, V.; Jouvet, P.-A.; Lantz, F. Long-term endogenous economic growth and energy transitions. Energy J. 2018, 39, 29-57. [CrossRef]

7. Brown, J.H.; Burnside, W.R.; Davidson, A.D.; DeLong, J.P.; Dunn, W.C.; Hamilton, M.J.; Mercado-Silva, N.; Nekola, J.C.; Okie, J.G.; Woodruff, W.H.; et al. Energetic Limits to Economic Growth. BioScience 2011, 61, 19-26. [CrossRef]

8. Režný, L.; White, J.B. Economic Growth and Hubbert Curve; Gaudeamus: Hradec Kralové, Czech Republic, 2013; pp. 473-484.

9. Smil, V. Energy at the Crossroads: Global Perspectives and Uncertainties, 1st ed.; The MIT Press: Cambridge, MA, USA; London, UK, 2003; ISBN 978-0-262-69324-0.

10. Wiedmann, T.O.; Schandl, H.; Lenzen, M.; Moran, D.; Suh, S.; West, J.; Kanemoto, K. The material footprint of nations. PNAS 2015, 112, 6271-6276. [CrossRef]

11. Incorporating Energy into Production Functions. Available online: https://www.debtdeflation.com/blogs/ 2016/08/19/incorporating-energy-into-production-functions/ (accessed on 29 June 2019).

12. Meadows, D.H.; Meadows, D.L.; Randers, J.; Behrens, W.W., III. The Limits to Growth: A Report for the Club of Rome's Project on the Predicament of Mankind, 1st ed.; Universe Books: New York, NY, USA, 1974; ISBN 978-0-87663-901-6.

13. Is Global Collapse Imminent? Available online: https:/espas.secure.europarl.europa.eu/orbis/sites/default/ files/generated/document/en/MSSI-ResearchPaper-4_Turner_2014.pdf (accessed on 29 June 2019).

14. Bardi, U. The Limits to Growth Revisited; Springer Briefs in Energy; Springer: New York, NY, USA, 2011; ISBN 978-1-4419-9415-8.

15. Fiddaman, T.S. Feedback Complexity in Integrated Climate-Economy Models. Ph.D. Thesis, Massachusetts Institute of Technology, Sloan School of Management, Cambridge, MA, USA, 1997.

16. Hall, C.A.S.; Powers, R.; Schoenberg, W. Peak Oil, EROI, Investments and the Economy in an Uncertain Future. In Biofuels, Solar and Wind as Renewable Energy Systems; Pimentel, D., Ed.; Springer: Dordrecht, The Netherlands, 2008; pp. 109-132. ISBN 978-1-4020-8653-3.

17. Sterman, J.D. The Energy Transition and the Economy: A System Dynamics Approach. Ph.D. Thesis, Massachusetts Institute of Technology, Sloan School of Management, Cambridge, MA, USA, 1981.

18. Ayres, R.; Warr, B. Accounting for growth: The role of physical work. Struct. Chang. Econ. Dyn. 2005, 16, 181-209. [CrossRef]

19. Uehara, T.; Nagase, Y.; Wakeland, W. Integrating Economics and System Dynamics Approaches for Modelling an Ecological-Economic System. Syst. Res. 2016, 33, 515-531. [CrossRef]

20. Capellán-Pérez, I.; Mediavilla, M.; de Castro, C.; Carpintero, Ó.; Miguel, L.J. Fossil fuel depletion and socio-economic scenarios: An integrated approach. Energy 2014, 77, 641-666. [CrossRef]

21. Radzicki, M.J. System Dynamics and Its Contribution to Economics and Economic Modeling. In Complex Systems in Finance and Econometrics; Meyers, R., Ed.; Springer: New York, NY, USA, 2009; pp. 727-737. ISBN 978-1-4419-7700-7.

22. Režný, L.; Bureš, V. Adding Feedbacks and Non-Linearity to the Neoclassical Growth Model: A New Realm for System Dynamics Applications. Systems 2018, 6, 8. [CrossRef]

23. Bardi, U. Mind Sized World Models. Sustainability 2013, 5, 896-911. [CrossRef]

24. Ayres, R.; Warr, B. The Economic Growth Engine: How Energy and Work Drive Material Prosperity, 2nd ed.; Edward Elgar Publishing: Cheltenham, UK, 2010; ISBN 978-1-84980-435-6.

25. Stern, D.; Kander, A. The Role of Energy in the Industrial Revolution and Modern Economic Growth; Centre for Applied Macroeconomic Analysis, Crawford School of Public Policy, The Australian National University: Canberra, Australia, 2011.

26. Hamilton, J.D. Causes and Consequences of the Oil Shock of 2007-08. Natl. Bur. Econ. Res. 2009, 40, $215-283$.

27. Hubbert, M.K. Nuclear Energy and The Fossil Fuels; Exploration and Production Division, Shell Development Company: San Antonio, TX, USA, 1956.

28. Brandt, A.R. Testing Hubbert. Energy Policy 2007, 35, 3074-3088. [CrossRef] 
29. Patzek, T.W.; Croft, G.D. A global coal production forecast with multi-Hubbert cycle analysis. Energy 2010, 35, 3109-3122. [CrossRef]

30. Bardi, U. Extracted How the Quest for Mineral Wealth is Plundering the Planet; Chelsea Green Publishing: Hartford, VT, USA, 2014; ISBN 978-1-60358-541-5.

31. Reynolds, D.B. The mineral economy: How prices and costs can falsely signal decreasing scarcity. Ecol. Econ. 1999, 31, 155-166. [CrossRef]

32. Ferroni, F.; Hopkirk, R.J. Energy Return on Energy Invested (ERoEI) for photovoltaic solar systems in regions of moderate insolation. Energy Policy 2016, 94, 336-344. [CrossRef]

33. The Real EROI of Photovoltaic Systems: Professor Hall Weighs in. Available online: http://www. resilience.org/stories/2016-05-27/the-real-eroi-of-photovoltaic-systems-professor-hall-weighs-in/ (accessed on 24 August 2017).

34. The Net EROI for Solar PV: A Case Study for Spain. Available online: http://docplayer.net/53311110The-net-eroi-for-solar-pv-a-case-study-for-spain-des-houches-march-7th-pedro-a-prieto.html (accessed on 29 June 2019).

35. Weißbach, D.; Ruprecht, G.; Huke, A.; Czerski, K.; Gottlieb, S.; Hussein, A. Energy intensities, EROIs (energy returned on invested), and energy payback times of electricity generating power plants. Energy 2013, 52, 210-221. [CrossRef]

36. Capellán-Pérez, I.; de Castro, C.; González, L.J.M. Dynamic EROI of the global energy system in future scenarios of transition to renewable energies. In Proceedings of the 3rd South East European Conference on Sustainable Development of Energy, Water and Environmental Systems (SDEWES), Novi Sad, Serbia, 30 June-4 July 2018.

37. IRENA. The Power to Change: Solar and Wind Cost Reduction Potential to 2025; International Renewable Energy Agency: Abu Dhabi, United Arab Emirates, 2016; p. 112.

38. Heinberg, R. Five Axioms of Sustainability. Available online: http://richardheinberg.com/178-five-axioms-ofsustainability (accessed on 11 September 2018).

39. Forrester, J.W. The Beginning of System Dynamics by Jay W. Forrester; Massachusetts Institute of Technology: Cambridge, MA, USA, 1989.

40. Ansell, T.; Cayzer, S. Limits to growth redux: A system dynamics model for assessing energy and climate change constraints to global growth. Energy Policy 2018, 120, 514-525. [CrossRef]

41. Mediavilla, M.; de Castro, C.; Capellán-Pérez, I.; Miguel, L.J.; Arto, I.; Frechoso, F. The transition towards renewable energies: Physical limits and temporal conditions. Energy Policy 2013, 52, 297-311. [CrossRef]

42. Davies, E.G.R.; Simonovic, S.P. Energy Sector for the Integrated System Dynamics Model for Analyzing Behaviour of the Social-Economic-Climatic Model; Department of Civil and Environmental Engineering the University of Western Ontario: London, ON, Canada, 2009; p. 189.

43. Rogelj, J.; Shindell, D.; Jiang, K.; Fifita, S.; Forster, P.; Ginzburg, V.; Handa, C.; Kobayashi, S.; Kriegler, E.; Mundaca, L.; et al. Mitigation Pathways Compatible with $1.5^{\circ} \mathrm{C}$ in the Context of Sustainable Development. In Global Warming of $1.5^{\circ} \mathrm{C}$. An IPCC Special Report on the Impacts of Global Warming of $1.5^{\circ} \mathrm{C}$ above Pre-Industrial Levels and Related Global Greenhouse Gas Emission Pathways, in the Context of Strengthening the Global Response to the Threat of Climate Change, Sustainable Development, and Efforts to Eradicate Poverty; IPCC: Geneva, Switzerland, 2018; p. 82.

44. Grubler, A. Energy transitions research: Insights and cautionary tales. Energy Policy 2012, 50, 8-16. [CrossRef]

45. Turner, G. A comparison of the Limits to Growth with thirty years of reality. Socio-Economics and the Environment in Discussion CSIRO Working Paper Series. Glob. Environ. Chang. 2008, 18, 341-538. [CrossRef]

46. Capellán-Pérez, I.; de Blas, I.; Nieto, J.; de Castro, C.; Miguel, L.J.; Mediavilla, M.; Carpintero, Ó.; Rodrigo, P.; Frechoso, F.; Cáceres, S. MEDEAS: D4.1 (D13) Global Model: MEDEAS-World Model and IOA Implementation at Global Geographical Level. 2017. Available online: https://www.medeas.eu/system/files/documentation/ files/Deliverable\%204.1\%20\%28D13\%29_Global\%20Model_MEDEAS-W\%201.1-inputs.xlsx (accessed on 29 June 2019).

47. Sers, M.R.; Victor, P.A. The Energy-emissions Trap. Ecol. Econ. 2018, 151, 10-21. [CrossRef]

48. Hirsch, R.L.; Bezdek, R.; Wendling, R. Peaking of World Oil Production: Impacts, Mitigation, and Risk Management; Cornell University: New York, NY, USA, 2005.

49. Trends in U.S. Military Spending. Available online: https://www.cfr.org/report/trends-us-military-spending (accessed on 12 September 2018). 
50. Johnson, Z. Financing the German Economy during the Second World War. West Bohemian Hist. Rev. 2017, 1, 115-143.

51. Nordhaus, W.; Sztorc, P. DICE 2013R: Introduction and User's Manual; Yale University: New Haven, CT, USA, 2013.

52. Newbold, S.C. Summary of the DICE Model; EPA: Washington, DC, USA, 2010.

53. Davies, E.G.R.; Simonovic, S.P. ANEMI: A new model for integrated assessment of global change. Interdiscip. Environ. Rev. 2010, 11, 127-161. [CrossRef]

54. Davies, E.G.R.; Simonovic, S.P. Global water resources modeling with an integrated model of the social-economic-environmental system. Adv. Water Resour. 2011, 34, 684-700. [CrossRef]

55. Sgouridis, S.; Csala, D. A Framework for Defining Sustainable Energy Transitions: Principles, Dynamics, and Implications. Sustainability 2014, 6, 2601-2622. [CrossRef]

(C) 2019 by the authors. Licensee MDPI, Basel, Switzerland. This article is an open access article distributed under the terms and conditions of the Creative Commons Attribution (CC BY) license (http://creativecommons.org/licenses/by/4.0/). 